\title{
Persistent Pneumothorax \\ Alveolar pleural fistula due to a hole in a bulla
}

Adil H. Al Kindi, "Jayakrishnan B., ${ }^{2}$ Saif M. Al Mubaihsi, ${ }^{2}$ Nasser A. Al Kemyani ${ }^{3}$

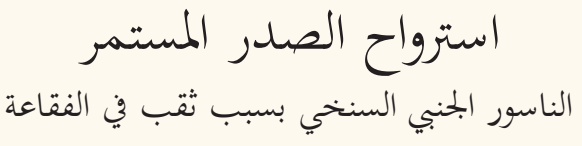

عادل حمد الكندي، جاياكريشنان بالاكريشنان، سيف محمد المبيحسي، ناصر عبد اله الكمياني
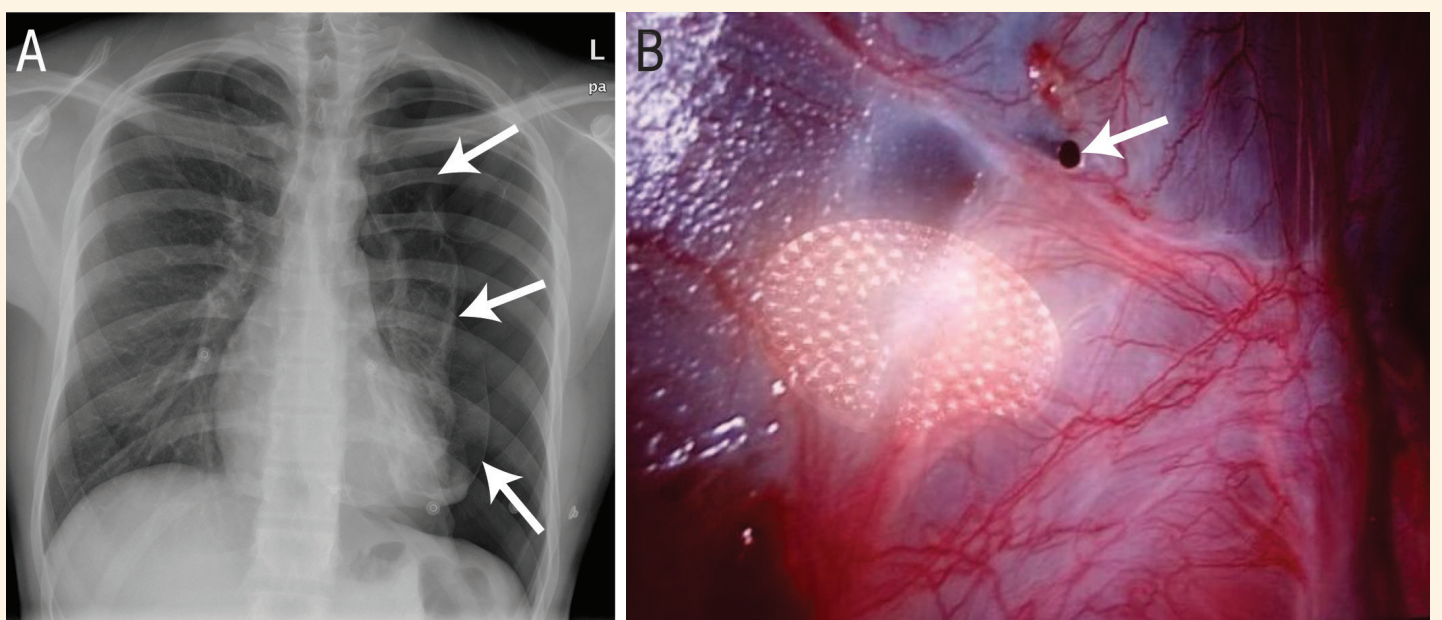

Figure 1: A: Chest X-ray of a 22-year-old male patient showing pneumothorax on the left side and collapsed lung margins (arrows). B: Thoracoscopic photograph showing a clean hole (arrow) in a bulla on the upper lobe of the left lung.

A 22-YEAR-OLD MALE PATIENT, PREVIOUSLY treated for pulmonary tuberculosis, presented to Sultan Qaboos University Hospital, Muscat, Oman in 2017 with sudden onset shortness of breath. Chest X-ray showed a pneumothorax on the left side [Figure 1A]. A 20F chest tube was placed and connected to a closed pleural drainage chamber with low suction. The lung failed to expand fully even after ten days. A computed tomography scan showed a large multiloculated pneumothorax with large bulla in the left apical region. Thoracoscopy revealed multiple emphysematous bullae in the left lung. Air was found to be leaking from a clean hole on one side of a large bulla in the left apex [Figure 1B]. This alveolar-pleural fistulalike behaviour probably accounted for the continuing air leak and the persistence of the pneumothorax. The left lung apex including the bullae was resected using an endo-GIA ${ }^{\mathrm{TM}}$ stapler (Medtronic plc, Minneapolis, Minnesota, USA). The staple line was covered with dissected parietal pleura. Mechanical pleurodesis was performed on the rest of the pleura. The lung subsequently inflated fully and remained expanded on follow-up one month later.

\section{Comment}

The major cause of persistent pneumothorax is an ongoing air leak, which is indicated by prolonged air bubbling into the chest drainage system. Air leaks are classified as: grade 1, during forced expiration (cough) only; grade 2, expiratory only; grade 3, inspiratory only; or grade 4, continuous. ${ }^{1}$ A common cause of persistent air leak is an alveolar-pleural fistula, a communication between the pulmonary parenchyma, distal to a segmental bronchus and the pleural space. This is different from a bronchopleural fistula which, by definition, is a communication between a main stem, lobar or segmental bronchus and the pleural space. 
Common causes include a ruptured bulla, cavitary neoplasm, fibrotic sarcoidosis, radiation fibrosis, interstitial lung diseases, necrotising pneumonia and postthoracic surgical intervention. ${ }^{2}$ This is often difficult to identify and is seldom seen as clearly as in the current patient.

\section{References}

1. Dugan KC, Laxmanan B, Murgu S, Hogarth DK. Management of persistent air leaks. Chest 2017; 152:417-23. https://doi. org/10.1016/j.chest.2017.02.020.

2. Chaturvedi A, Lee S, Klionsky N, Chaturvedi A. Demystifying the persistent pneumothorax: Role of imaging. Insights Imaging 2016; 7:411-29. https://doi.org/10.1007/s13244-016-0486-5. 